\title{
A 3-Synapse Positive Feedback Loop Regulates the Excitability of an Interneuron Critical for Sensitization in the Leech
}

\author{
Kevin M. Crisp ${ }^{1}$ and Kenneth J. Muller ${ }^{1,2}$ \\ ${ }^{1}$ Department of Physiology and Biophysics, University of Miami School of Medicine, and ${ }^{2}$ Neuroscience Program, University of Miami, Miami, Florida \\ 33136
}

\begin{abstract}
Sensitization of reflexive shortening in the leech has been linked to serotonin (5-HT)-induced changes in the excitability of a single interneuron, the $\mathrm{S}$ cell. This neuron is necessary for sensitization and complete dishabituation of reflexive shortening, during which it contributes to the sensory-motor reflex. The $S$ cell does not contain 5-HT, which is released primarily from the Retzius (R) cells, whose firing enhances S-cell excitability. Here, we show that the S cell excites the R cells, mainly via a fast disynaptic pathway in which the first synapse is the electrical junction between the $S$ cell and the coupling interneurons, and the second synapse is a glutamatergic synapse of the coupling interneurons onto the $\mathrm{R}$ cells. The $\mathrm{S}$ cell-triggered excitatory postsynaptic potential in the $\mathrm{R}$ cell diminishes and nearly disappears in elevated concentrations of divalent cations because the coupling interneurons become inexcitable under these conditions. Serotonin released from the $\mathrm{R}$ cells feeds back on the $\mathrm{S}$ cell and increases its excitability by activating a 5- $\mathrm{HT}_{7}$-like receptor; 5-methoxytryptamine (5-MeOT; $10 \mu \mathrm{M}$ ) mimics the effects of 5-HT on S cell excitability, and effects of both 5-HT and 5-MeOT are blocked by pimozide $(10 \mu \mathrm{M})$ and SB-269970 [(R)-3-(2-(2-(4-methylpiperidin-1-yl)-ethyl)pyrrolidine-1-sulfonyl)phenol] (5 $\mu \mathrm{M})$. This feedback loop may be critical for the full expression of sensitization of reflexive shortening.
\end{abstract}

Key words: serotonin; serotonin receptor; electrical coupling; shortening; reflex; circuits

\section{Introduction}

Research into the cellular mechanisms of learning and memory has focused less on changes in intrinsic neuronal excitability than on changes in synaptic strength. Activity-dependent increase in excitability can function as a homeostatic mechanism that compensates for prolonged periods of lowered activity (Desai et al., 1999). However, changes in excitability can also be nonhomeostatic and contribute to plasticity in neural networks, as when intracellular depolarization of cerebellar deep nuclei neurons enhances their repetitive firing in response to future stimulation (Aizenman and Linden, 2000). Neuromodulators such as serotonin (5-HT) appear to play an important role in the regulation of excitability and certain forms of learning. For example, release of 5-HT enhances the excitability of sensory neurons contributing to the sensitization of the tail withdrawal reflex in Aplysia (Marinesco and Carew, 2002).

In the leech, 5-HT increases the excitability of the S interneuron (Burrell et al., 2001), which is critical for sensitization of the whole body shortening reflex (Modney et al., 1997; Burrell et al.,

Received July 23, 2005; revised Jan. 24, 2006; accepted Jan. 25, 2006.

This work was supported by National Institutes of Health Grant R01-NS34927. We thank Drs. Tony DeFazio and Stephen Roper for use of and assistance with confocal microscopy, and Drs. Brian Burrell, Gerhard Dahl, Yuanli Duan, Emmanuel Ngu, Christie Sahley, and Alec Urazaev, together with Ginny Cruz and Jeff Lipitz, for helpful discussions.

Correspondence should be addressed to Kevin M. Crisp, Assistant Professor, Biology Department, Saint Olaf College, 1520 Saint Olaf Avenue, Northfield, MN 55057. E-mail: crisp@stolaf.edu. D0I:10.1523/JNEUROSCI.3056-05.2006

Copyright $\odot 2006$ Society for Neuroscience $\quad 0270-6474 / 06 / 263524-08 \$ 15.00 / 0$
2003). Like the tail-withdrawal reflex in Aplysia, the whole body shortening reflex is mediated in part by a monosynaptic reflex arc in which sensory neurons terminate directly onto motor neurons and by multisegmental interneurons (Shaw and Kristan, 1995). The same sensory neurons also excite the $S$ interneuron, which provides additional excitatory input to the motor neurons, but the $\mathrm{S}$ cell cannot, on its own, shorten the animal. With sensitization, weak stimuli that shorten the animal evoke an increased number of S-cell impulses that, acting through motoneurons, enhance shortening (Sahley et al., 1994). The $\mathrm{S}$ cell thus appears to be recruited into the circuit (supplemental Fig. 1, available at www.jneurosci.org as supplemental material). The sensitizationinduced increase in the excitability of the $S$ cell is mimicked by 5-HT application (Burrell et al., 2001), is blocked by the 5-HT receptor antagonist methysergide, and uses CAMP as a second messenger (Burrell et al., 2005). Moreover, the receptors mediating the effects of 5-HT on the $S$ cell are unknown. The $S$ cell does not contain 5 -HT, but the firing of the serotonergic Retzius (R) cells, the main source of 5-HT in the leech (Lent et al., 1991), enhances the excitability of the $S$ cell (Burrell et al., 2001). The link between the sensitizing stimulus and 5-HT release, however, has remained elusive.

Although strong mechanical or electrical stimuli activate the Retzius cells and cause 5-HT release, the direct excitatory inputs to the R cells are unknown. The present study aimed to determine (1) whether the $S$ cell itself contributes to that excitation and (2) the 5 -HT receptor subtypes on the $S$ cell by which the $\mathrm{R}$ cell may increase the excitability of the $\mathrm{S}$ cell. 


\section{Materials and Methods}

Preparation and solutions. Leeches (2-3 g) were supplied commercially (Leeches USA, Westbury, NY) and maintained in artificial pond water $(0.5 \mathrm{~g} / \mathrm{L}$ Forty Fathoms salts in deionized water; Marine Enterprises, Baltimore, MD) at $15^{\circ} \mathrm{C}$. Unless otherwise stated, experiments were performed in a physiological saline solution containing the following (in $\mathrm{mm}$ ): $115 \mathrm{NaCl}, 4.0 \mathrm{KCl}, 1.8 \mathrm{CaCl}_{2}$, and 10 Tris maleate, at pH 7.5 (Kuffler and Potter, 1964). In some experiments, $18 \mathrm{~mm} \mathrm{MgCl}_{2}$ was added to physiological saline, or $15 \mathrm{~mm} \mathrm{MgCl}_{2}$ and $18 \mathrm{~mm} \mathrm{CaCl}_{2}$ replaced equimolar concentrations of $\mathrm{NaCl}$. The $\mathrm{S}$ cell has no IPSPs and a brief, overshooting action potential in the soma, which is typically adjacent to the R cells. With the largest axon in the connectives, the action potentials of the $\mathrm{S}$ cell are ordinarily the largest units recorded extracellularly from the connectives.

Electrophysiological recording. Intracellular recordings were obtained using thin-walled glass capillaries (30-30-0; Frederick-Haer, Brunswick, $\mathrm{ME}$ ), drawn on a Flaming/Brown micropipette puller (model P-97; Sutter Instruments, Novato, CA) to a resistance of 25-30 $\mathrm{M} \Omega$ when filled with $4 \mathrm{M}$ potassium acetate. Extracellular signals were amplified differentially with an AC preamplifier (model P15; Grass Telefactor, West Warrick, RI). Intracellularly recorded signals were amplified (model M701 Microprobe system; World Precision Instruments, Sarasota, FL; or model 1600 Neuroprobe amplifier; AM Systems, Carlsborg, WA), filtered with a low-pass bessel filter (modified model LPF202A; Warner Instruments, Hamden, CT), and digitized using the Digidata 1322A interface and Axoscope data acquisition software (Molecular Devices, Union City, CA). Stimulus pulses were delivered using an S88 dualoutput square-pulse stimulator and an SIU5 stimulus isolation unit (Grass Telefactor).

Dye injections and microscopy. To identify potential synaptic contact sites, in some ganglia the $\mathrm{S}$ cell and an $\mathrm{R}$ cell were filled with different intracellular tracers. In these experiments, $3 \%$ Lucifer yellow (LY) in $0.1 \mathrm{M} \mathrm{LiCl}$ was injected into the Retzius cell and either 5\% biocytin (Invitrogen, Eugene, OR) in $0.4 \mathrm{M} \mathrm{KCl}$ containing $0.4 \%$ fast green $\mathrm{FCF}$ dye or $10 \mathrm{mg} / \mathrm{ml}$ rhodamine-dextran (Invitrogen) in $0.2 \mathrm{M} \mathrm{KCl}$ containing $0.4 \%$ fast green FCF dye was injected into the $S$ interneuron through thick-walled recording microelectrodes (30-31-1; Frederick-Haer) beveled to a resistance of 40-60 $\mathrm{M} \Omega$ when measured in the recording chamber. When biotin was injected into the S cell, it also filled the coupling interneurons, which are electrically coupled to the $S$ cell. After cells were injected, ganglia were fixed for $1 \mathrm{~h}$ in $4 \%$ paraformaldehyde, rinsed in saline, and stained overnight at $15^{\circ} \mathrm{C}$ in $10 \mu \mathrm{g} / \mathrm{ml}$ streptavidin conjugated to Texas Red (Invitrogen) in saline. Ganglia were then rinsed in saline, dehydrated through an ascending ethanol series, cleared in 100\% xylenes, and mounted on glass slides in Gurr fluoromount mountant (BDH, Poole, UK). These preparations were imaged on an Olympus (Melville, NY) FluoView FV300/BX61 laser scanning confocal microscope mounted on an Olympus BX50WI upright microscope platform. The Lucifer yellow fluorophore was excited with $488 \mathrm{~nm}$ light from an argon laser and imaged with a $510 \mathrm{~nm}$ long pass barrier filter. The Texas Red and rhodamine fluorophores were excited with $568 \mathrm{~nm}$ light from a krypton laser and imaged through a $550 \mathrm{~nm}$ short-pass barrier filter. The FluoView imaging software (version 2.1.39; Olympus) was used for image acquisition; Image (version 1.32j, developed by Wayne Rasband of the National Institutes of Health, Bethesda, MD) was used for projection of the full z-stack. Adobe Photoshop (version 6.0; Adobe Systems, Mountain View, CA) was used for image processing and the uniform enhancement of contrast.

In some experiments, $S$ interneurons were injected with $0.2 \mathrm{M} \mathrm{(5)6-}$ carboxyfluorescein (6-CF; Eastman Kodak Company, Rochester, NY) recrystalized, dissolved in deionized water, and neutralized to $\mathrm{pH} 7.4$ with $\mathrm{KOH}$. Injection of the $\mathrm{S}$ cell with 6-CF reveals the two coupling interneurons in each ganglion to which the $S$ cell is coupled by nonrectifying electrical junctions (Muller and Scott, 1981). Because 6-CF diffuses readily from the $S$ cell into the coupling interneurons, the locations of the somata of the latter cells can be seen by illuminating the ganglion with light from a tungsten lamp operated at higher-than-rated voltage and passed through a BG12 filter. The blue light was focused through a

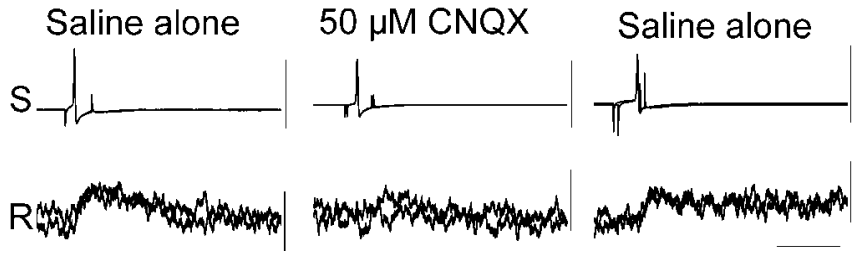

Figure 1. Single impulses elicited from the S cell triggered a short-latency EPSP in the serotonergic $R$ cell. A single action potential in the $S$ cell evoked by a depolarizing intracellular current injection and the resulting short-latency EPSP are shown (left). After a 3-4 min treatment with AMPA/kainate receptor antagonist CNQX $(50 \mu \mathrm{m})$ in saline, the EPSP in the R cell was eliminated (middle). When the CNQX was replaced with saline alone, the EPSP mostly recovered (right). Calibration: top traces, $-60 \mathrm{mV}$ beginning at $0 \mathrm{mV}, 50 \mathrm{~ms}$; bottom traces, $-1 \mathrm{mV}$ beginning at $-41 \mathrm{mV}, 50 \mathrm{~ms} ;-43 \mathrm{mV}, 50 \mathrm{~ms} ;-41 \mathrm{mV}, 50 \mathrm{~ms}$, respectively.

Leitz (Wetzlar, Germany) dark-field condenser (numerical aperture, $0.8-0.95)$ onto the ganglion, which was viewed through a yellow barrier filter.

Effects of drugs on excitability and synaptic transmission. The excitability of the S cell was evaluated by the methods of Burrell et al. (2001) by measuring (1) the threshold amplitude of current required to evoke an action potential within the first $10-15 \mathrm{~ms}$ of a $20 \mathrm{~ms}$ pulse, and (2) the number of impulses elicited by a $200 \mathrm{~ms}$ pulse of threshold amplitude current. Changes in excitability (e.g., before and after drug treatment) were considered valid only if input resistance and resting membrane potential of the $S$ cell did not change, because damage caused by the impaling electrode might artifactually change soma excitability. This does not rule out input resistance changes distal from the soma as potential mechanisms of the enhanced excitability; such changes in input resistance might not be detected from the soma. 5-HT, 5-methoxytryptamine (5-MeOT), pimozide, methysergide, and (R)-3-(2-(2-(4methylpiperidin-1-yl)-ethyl)pyrrolidine-1-sulfonyl)phenol (SB-269970) were obtained from Sigma-Aldrich (St. Louis, MO). Drugs were prepared at their final concentration in either physiological saline or saline with $18 \mathrm{~mm} \mathrm{MgCl}_{2}$. Because pimozide was dissolved in ethanol, all salines for sets of experiments in which pimozide was used for one or more drug conditions contained $0.15 \%$ ethanol. After a baseline measurement of excitability was obtained, ganglia were incubated in pretreatment saline or antagonist pimozide for $2 \mathrm{~min}$, then treatment saline (containing agonist, antagonist, agonist plus antagonist, or no drug) for $2 \mathrm{~min}$. Then, ganglia were washed with saline for $5 \mathrm{~min}$ at a flow rate of $1 \mathrm{ml} / \mathrm{min}$, after which the second and final measurement of excitability was made. In treatments involving an antagonist, the same antagonist was always used in both pretreatment and treatment salines. The experimenter was blind to the drugs applied.

In some experiments, intracellular stimulation of the R cell was used in place of bath-applied 5-HT or 5-MeOT to enhance the excitability of the $S$ cell. In these experiments, measurements of the excitability of the $S$ cell were made before and immediately (i.e., without any delay) after a $10 \mathrm{~s}$ train of suprathreshold depolarizing current pulses delivered at a rate of $4 \mathrm{~Hz}$, after the method of Burrell et al. (2001).

Statistics. Statistical analyses were conducted using Statistica (version 5.1; StatSoft, Tulsa, OK). Averages are reported as the mean \pm SEM.

\section{Results}

\section{$S$ cell to $R$ cell connection}

Single action potentials in the S cell evoked by intracellular current injection triggered a short latency EPSP in the R cell (Fig. 1). When multiple traces of the EPSP were averaged, the delay was measured to be $\sim 2.5 \mathrm{~ms}$ in duration ( 9 sweeps) (data not shown), which is on the order of previously described monosynaptic chemical connections in the leech, such as the connection from the P cell to the S cell (Baccus et al., 2000). The EPSP was abolished by the AMPA/kainate receptor antagonist CNQX (50 $\mu \mathrm{M})$ (Fig. 1). Other established glutamatergic synapses in the leech are 


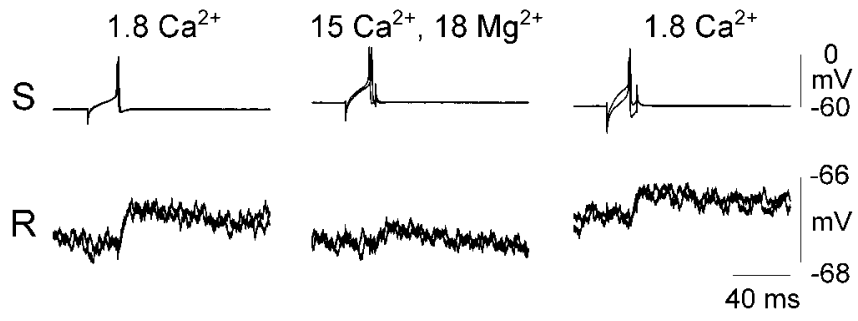

Figure 2. The connection from the $S$ cell to the $R$ cell was polysynaptic. The EPSP observed in the $R$ cell in physiological saline (left) was largely abolished in high divalent cation-containing saline (18 $\left.\mathrm{mm} \mathrm{Mg}^{2+}, 15 \mathrm{~mm} \mathrm{Ca}^{2+}\right)$, suggesting that the connection is polysynaptic (middle). On returning to physiological saline, the EPSP recovered (right).

also blocked by 25-50 $\mu \mathrm{M}$ CNQX (Wessel et al., 1999; Baccus et al., 2000).

Although the above observations suggested the presence of a monosynaptic connection of the $\mathrm{S}$ cell with the $\mathrm{R}$ cell, a well established test for monosynaptic chemical connections used originally in the leech is to raise both $\left[\mathrm{Ca}^{2+}\right]$ and $\left[\mathrm{Mg}^{2+}\right]$ in the bath (Nicholls and Purves, 1970). The rationale is that extracellular calcium and magnesium ions each decrease the excitability of neurons (Frankenhaeuser and Hodgkin, 1957) and have opposite effects on the number of quantal packets secreted at chemical synapses (Katz, 1962). Thus, if there is an excitable interneuron involved, it will not fire and the synaptic potential will disappear, whereas monosynaptic potentials persist. When ganglia were perfused with saline containing high divalent cations (18 $\mathrm{mM} \mathrm{MgCl}_{2}$ and $15 \mathrm{mM} \mathrm{CaCl}_{2}$ ), the EPSP usually observed in the $\mathrm{R}$ cell in response to an $\mathrm{S}$ cell action potential was largely abolished (Fig. 2). A small residual EPSP was occasionally observed up to $4 \mathrm{~min}$ into the perfusion of high divalent cation saline (Fig. 2, middle). It is possible that this indicates the presence of a relatively weak monosynaptic connection from the $\mathrm{S}$ onto the $\mathrm{R}$, in addition to a stronger polysynaptic connection. A second possibility also consistent with the data presented below is that the connection is entirely polysynaptic and the decrease in excitability of the interneuron prevents most, but not all, of its presynaptic sites from depolarizing to threshold for synaptic release. Similarly, conduction block in P sensory neurons has been shown to cause stepwise reductions in EPSP amplitude in the S cell because of a failure of impulses to invade all of the spatially distributed synaptic contact sites under certain conditions (Baccus et al., 2000). Nevertheless, these data suggest that most of the synaptic transmission from the $\mathrm{S}$ interneuron to the $\mathrm{R}$ cell is mediated by a fast polysynaptic connection.

\section{Contacts with the $\mathrm{R}$ cell}

To determine whether and where the $\mathrm{S}$ cells contact the $\mathrm{R}$ cells, $\mathrm{R}$ cells were filled with the fluorescent dye LY, and S cells were filled with biocytin. Biocytin was labeled in fixed ganglia with a streptavidin-Texas Red conjugate. Because the $S$ cell and the coupling interneurons are electrically coupled and dye-coupled (Muller and Scott, 1981), biocytin readily diffused from the S cell into the coupling interneurons, filling both. The dye-coupling, properties of electrical synapses, and distribution of processes and contacts between the $S$ cell and the coupling interneurons have been described (Muller and Scott, 1981).

Biocytin fills of the $\mathrm{S}$ cell (and coupling interneurons) together with LY fills of the $\mathrm{R}$ cells viewed at high resolution by confocal microscopy revealed many potential synaptic contact sites. In electron microscopic studies of labeled sensory and motor neurons in the leech, synaptic contacts were seen whenever the neurons appeared to make contact at the light microscopic level (Macagno et al., 1987), suggesting that apparent contacts at varicosities are generally sites of synapses. Nonetheless, definitive identification of a contact as a synapse requires electron microscopy to eliminate the possibility of an intervening glial sheet. Apparent contacts were observed between the cell filled with Lucifer yellow ( $\mathrm{R}$ cell) and the cells filled with biocytin ( $\mathrm{S}$ cell and coupling interneurons). The white dotted lines in Figure 3 delineate the lateral extent of the $S$ cell arbor; processes between the dotted lines may belong to either the $\mathrm{S}$ cell or coupling interneurons, but processes outside the region between the dotted lines are elements of the coupling interneuron arbors (Muller and Scott, 1981). Because the processes of the R cell do not extend far beyond the midline into the contralateral hemiganglion, more contact sites were observed between the $\mathrm{R}$ cell and the ipsilateral processes of the coupling interneurons than between the $\mathrm{R}$ cell and the contralateral processes of the coupling interneurons. The $\mathrm{R}$ cell releases 5 -HT in a paracrine manner from its soma (Trueta et al., 2003, 2004) and also forms chemical junctions (Liu and Nicholls, 1989). The R cell had many varicosities that appeared to contact the main axon and primary neurite of the $S$ cell. Because synaptic vesicles are never observed in the main axon or initial neurite of the S cell (Muller and Scott, 1981), these may be sites from which 5-HT is released and modulates the excitability of the $S$ cell.

In a lateral region outside the $\mathrm{S}$ cell arbor, as determined previously (Muller and Scott, 1981), and within the coupling interneuron arbor, varicosities along branches of the ipsilateral coupling interneuron appeared to make contacts with the R cell (Fig. $3 A$, arrowhead). The lateral location of the putative synaptic contacts with the $\mathrm{R}$ cell when viewed without the overlying fill of the $\mathrm{R}$ cell (Fig. 3B, arrowhead) showed they were made by a coupling interneuron rather than the $S$ cell. The presence of such contact sites suggests that the coupling interneurons may mediate the $\mathrm{S}-\mathrm{R}$ connection. These putative contact sites indicated by the arrowheads (Fig. $3 A, B$ ) are shown at a higher magnification in Figure $3 C$.

Additional dual cell fills were performed in which the $S$ cell was filled with a high-molecular-weight dextran conjugated to Texas Red dye. Because the dextran did not pass through gap junctions and fill the coupling interneurons, it was possible to identify potential contact sites between the $\mathrm{R}$ cell and the $\mathrm{S}$ cell without the coupling interneurons. In comparison to the $321 \pm$ 30 potential contact sites observed between S cells, coupling interneurons and R cells using biocytin injections $(n=2)$, dextraninjected $S$ cells revealed $126 \pm 11$ potential contact sites $(n=2)$. About one-half of these contact sites appeared to be varicosities of the $\mathrm{R}$ cell in close association with the axon and primary neurite of the $S$ cell, consistent with an action of the R cell directly on the $\mathrm{S}$ cell. Although the interpretation of these morphological observations is limited, they are also consistent with our interpretation from the electrophysiological data that chemical transmission from the $\mathrm{S}$ cell to the $\mathrm{R}$ cell is principally indirect and mediated by the coupling interneurons, with possibly a weak direct chemical connection from the $\mathrm{S}$ cell onto the $\mathrm{R}$ cell.

\section{Coupling interneurons in high divalent cations}

The $S$ cell and the coupling interneurons are tightly coupled electrically, such that each action potential in the $\mathrm{S}$ cell evokes an action potential in the coupling interneurons, and vice versa (Muller and Scott, 1981). Because the EPSPs recorded in the $\mathrm{R}$ cell in response to $S$ cell action potentials were largely abolished in high divalent cation saline, it seemed likely that the $S$ cell failed to 

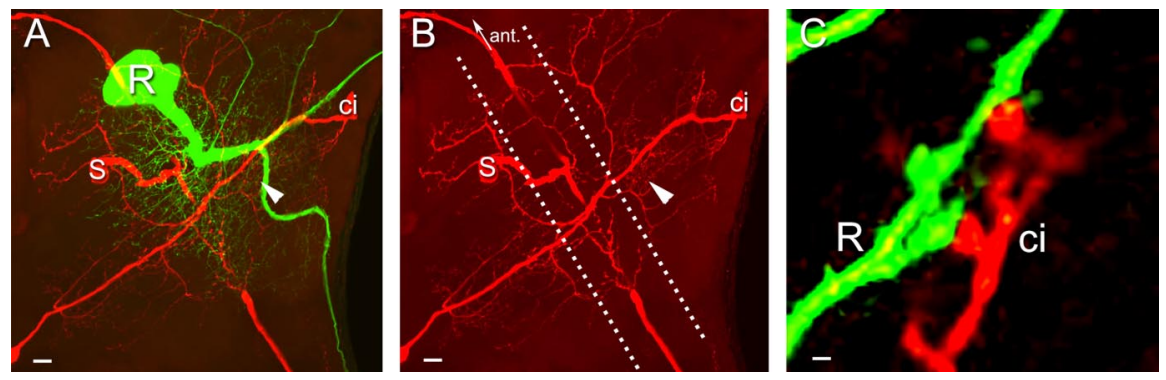

Figure 3. Laser-scanning confocal micrograph of putative synaptic contact sites between the coupling interneurons and the $R$ cells. $\boldsymbol{A}, A n R$ cell (R) and an S cell (S) in the same ganglion were filled with Lucifer yellow (green) and biocytin (red), respectively. The biocytin was stained with a streptavidin-Texas Red conjugate. When the $S$ cell was injected with biocytin, the coupling interneurons (ci) were also filled, of which the soma of only one is visible in this portion of the ganglion. The arrowhead indicates the site of possible synaptic contacts between the $R$ cell and a coupling interneuron. $B$, Same image as $A$, but without the $R$ cell to show the $S$ cell and the coupling interneurons. The white dotted lines delineate the lateral extent of the arbor of the $S$ cell, which is small and medial. Because the projections of the coupling interneurons cross the midline, processes between the dotted lines are medial and include all of the processes of the $S$ cell and some of the ci cells, but processes beyond the dotted lines belong to the ci cells. The arrowhead again indicates the location of the observed contact sites, within the arbor of the right-hand coupling interneuron and quite lateral of the arbor of the $\mathbf{S}$ cell. The midline is marked by the arrow pointing toward the anterior (ant.). $\boldsymbol{C}$, High magnification ( $60 \times$ with a $10 \times$ zoom) detail of contact sites indicated by the arrow in $\boldsymbol{A}$ and $\boldsymbol{B}$ is shown in a single section. Presynaptic coupling interneuron processes are shown in red; postsynaptic $R$ cell processes are shown in green. Number of optical sections per image: $\boldsymbol{A}, 13 ; \boldsymbol{B}, 13 ; \boldsymbol{C}, 1$. Section interval: $\boldsymbol{A}, 3 \mu \mathrm{m} ; \boldsymbol{B}, 3 \mu \mathrm{m} ; \boldsymbol{C}, 0.3 \mu \mathrm{m}$. Scale bars: $\boldsymbol{A}, \boldsymbol{B}, 10 \mu \mathrm{m} ; \boldsymbol{C}, 0.4 \mu \mathrm{m}$.

interneuron impulse recorded in the soma was $\sim 10-20 \mathrm{mV}$ in amplitude. Within the first 2 min of high divalent cation saline perfusion, the amplitude of the coupling interneuron action potential was reduced to $<5 \mathrm{mV}$. An example of this decrease in the excitability of the coupling interneuron is shown in Figure 4. Note that, because the $\mathrm{S}$ cell impulse was recorded from the connectives leaving the ganglion, the impulse in the coupling interneuron appeared artifactually to precede the action potential in the $\mathrm{S}$ cell. The input resistance of the coupling interneuron was $8-10 \mathrm{M} \Omega$ and its resting membrane potential was between $50-55 \mathrm{mV}$. The input resistance did not change during perfusion of high divalent cationcontaining saline, and the membrane potential hyperpolarized by a few millivolts as the action potential decreased in amplitude.

The strong electrical junction between the $S$ cell and the coupling interneurons,
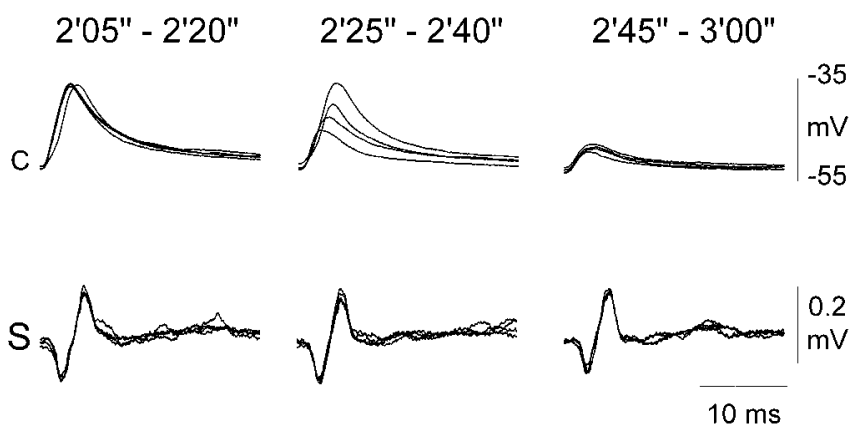

Figure 4. Progressive decrease in excitability of the coupling interneuron (C) during perfusion of saline containing high divalent cations ( $18 \mathrm{~mm} \mathrm{MgCl}_{2}$ and $15 \mathrm{~mm} \mathrm{CaCl}_{2}$ ). The $\mathrm{S}$ cell was filled with 6-carboxyfluorescein, which also filled the coupling interneurons, making them fluorescent and visible with suitable filters for impalement and recording with a sharp microelectrode (top traces). The $S$ cell was stimulated extracellularly with a suction electrode by delivering an electrical shock just above $S$ cell threshold to the anterior connectives. The bottom traces show extracellular recordings of the $S$ cell action potentials using a suction electrode applied to the posterior connective (S), where it arrived after exciting the coupling interneuron. Although the 12 traces shown in the figure were consecutive with little change in the $S$ cell action potential, the resting membrane potential, or input resistance of the coupling interneuron, the action potential in the coupling interneuron decreased by $\sim 70 \%$ during 2 min of perfusion with the high divalent cation saline.

elicit impulses in the coupling interneurons under these conditions, blocking coupling interneuron release of glutamate onto the $\mathrm{R}$ cell. To test this hypothesis, intracellular recordings from the coupling interneuron were obtained in physiological saline and during perfusion of high divalent cation saline. To see the coupling interneurons, the S cell was injected with carboxyfluorescein dye, and the coupling interneurons were located by their fluorescence. To determine whether the impulse in the coupling interneurons failed to be elicited by activity in the $S$ cell, the $S$ cell was stimulated extracellularly just above threshold with a suction electrode on the anterior connectives. Simultaneous recordings from the posterior connectives showed the $S$ cell action potential and the extent to which fibers other than the $S$ cell were excited by the extracellular stimulus. In physiological saline, the coupling and the rapid conduction of $S$ cell action potentials into the coupling interneuron (Muller and Scott, 1981) explain how the polysynaptic connection from the $S$ cell to the $R$ cell can generate EPSPs at such a short latency and appear in many respects monosynaptic. Thus, although in high magnesium salines (1) conduction continues between S cells (not shown) and (2) persistence of a synaptic potential in such solutions has been routinely used to help demonstrate that a synapse is electrical rather than chemical (Nicholls and Purves, 1970), the high divalent cation technique in this situation, with an excitable interneuron, distinguished between monosynaptic and polysynaptic connections, even with one synapse electrical rather than chemical.

The amplitude of action potentials recorded in the coupling interneuron soma in response to $\mathrm{S}$ cell action potentials at $1 \mathrm{~Hz}$, as shown in Figure 4, declined in intermittently decreasing steps $(n=2)$. This variability in amplitude was only observed during the initial perfusion of high divalent cations; the action potential recorded in physiological saline appeared fixed in amplitude and the residual depolarization (of a few millivolts) observed toward the end of the 2 min perfusion was of constant amplitude. The residual depolarization in the inexcitable soma of the coupling interneuron might have been caused by the passive spread of action potentials from the $S$ cell, as described below. It is possible that this residual depolarization brought a small subset of presynaptic sites to threshold resulting in the minor, persistent EPSP sometimes observed in high divalent cations (Fig. 2, middle), although there might also have been a direct connection on the $\mathrm{R}$ cell from the $S$ cell.

One untested explanation for the stepwise decline is that separate branches of the coupling interneuron contacting the $S$ cell may each have been separately excitable, and that activity in some branches blocked when in others it did not. This has been demonstrated for sensory neurons in the leech (Muller and Scott, 1981; Macagno et al., 1987; Gu et al., 1989, 1991). The recording in the inexcitable soma of the coupling interneuron would therefore show the sum of activity in multiple branches contacting the $S$ cell branches and perhaps the contralateral coupling interneuron. Similarly, cell 204 generates action potentials in two different axon branches almost simultaneously, which can summate into 
A

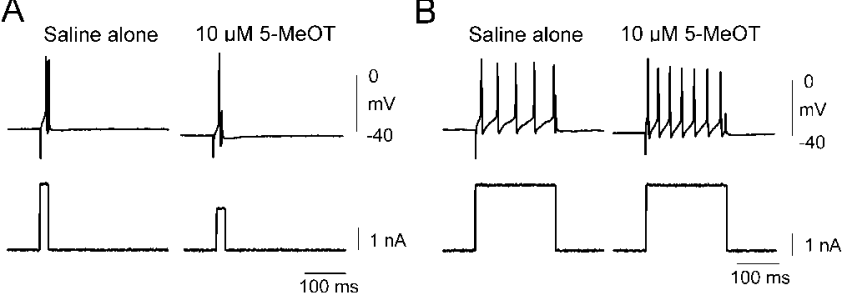

Figure 5. Bath applied 5-MeOT directly enhanced the excitability of the $S$ cell in the presence of $18 \mathrm{~mm} \mathrm{Mg}^{2+}$ to block chemical transmission. A, A 2 min application of 5-Me0T (10 $\left.\mu \mathrm{M}\right)$ decreased the threshold current required to elicit an action potential within the first $10-15 \mathrm{~ms}$ of a 20 ms intracellular current pulse in the $S$ cell. $\boldsymbol{B}$, The same 5-Me0T treatment increased the number of impulses evoked by a $200 \mathrm{~ms}$ current pulse at the threshold level of the current (determined in $\boldsymbol{A}$ ).

what appears to be a single action potential in the inexcitable soma (Weeks, 1981). Interestingly, as the impulse recorded in the coupling interneuron decreased in amplitude, the initial rise time of the impulse remained relatively constant. This would not have occurred had the coupling interneuron action potential, even if spread passively, simply declined in amplitude or if the numbers of active branches declined. A simple explanation is that, instead, the initial rise was caused by the synaptic current from the $\mathrm{S}$ cell, which did not decline, and that the later stepwise component was caused by the spread of impulses in a decreasing number of branches of the coupling interneuron. An alternative, less likely explanation is that impulse initiation sites farther from the soma failed first, and that the residual impulse was a subset of more proximal impulse initiation sites that did not fail.

\section{5-HT feedback onto the $\mathrm{S}$ cell}

The excitation of the $\mathrm{R}$ cell by the $\mathrm{S}$ cell through the coupling interneurons is believed in turn to cause a release of 5-HT by the $\mathrm{R}$ cells that feed back on the $\mathrm{S}$ cell to enhance its excitability. Previous work has demonstrated that 5-HT enhances the excitability of the $S$ cell in a cAMP-dependent manner (Burrell et al., 2001; Burrell and Sahley, 2005). Of the seven families of 5-HT receptors (5-HTRs), only $5-\mathrm{HT}_{4} \mathrm{R}, 5-\mathrm{HT}_{6} \mathrm{R}$, and $5-\mathrm{HT}_{7} \mathrm{R}$ are reported to be positively coupled to cAMP (Raymond et al., 2001). At low concentrations, 5-MeOT is a selective agonist for these three receptors. 5-MeOT $(10 \mu \mathrm{M})$ relaxes the leech pharyngeal muscle, whereas $5-\mathrm{HT}_{1} \mathrm{R}, 5-\mathrm{HT}_{2} \mathrm{R}$, and $5-\mathrm{HT}_{3} \mathrm{R}$ agonists induce contractions of this muscle (O'Gara et al., 1999).

To determine whether 5-MeOT mimicked the effects of 5-HT in increasing $S$ cell excitability, two measures of excitability were used. To block neurotransmitter release and indirect effects of 5-MeOT, ganglia were perfused for $10 \mathrm{~min}$ with saline containing $18 \mathrm{mM} \mathrm{Mg}^{2+}$, then the same solution containing $10 \mu \mathrm{M}$ 5-MeOT for $2 \mathrm{~min}$, followed by washing for $5 \mathrm{~min}$ in the same solution without drug to terminate 5-HTR activation and to allow the full effects of cAMP/protein kinase A activation to occur. Excitability was measured before applying the drug and after a $5 \mathrm{~min}$ wash. Excitability was measured by both the threshold current required to elicit an impulse within $10-15 \mathrm{~ms}$ during a $20 \mathrm{~ms}$ pulse, and by the number of action potentials induced by a $200 \mathrm{~ms}$ current pulse at the current threshold, as determined during the first measurement. The current threshold decreased in 5-MeOT and the number of impulses per $200 \mathrm{~ms}$ pulse at the original threshold current increased without inducing detectable changes in the input resistance or membrane potential (Fig. 5).

The effect of 5-MeOT and previous work showing that methysergide blocks the enhancement of S cell excitability by $5-\mathrm{HT}$

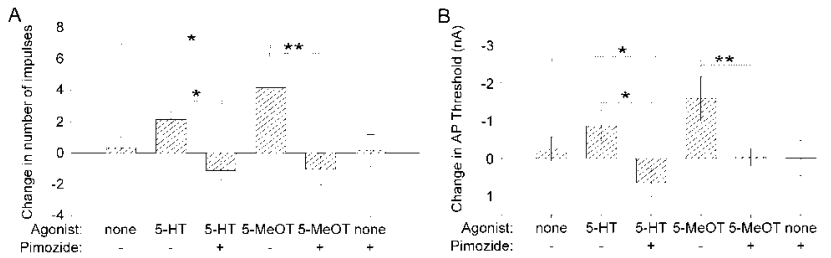

Figure 6. Pimozide, an antagonist of $5-\mathrm{HT}_{7}$ receptors, blocked the effects of $5-\mathrm{Me} 0 \mathrm{~T}$ on $\mathrm{S}$ cell excitability in $18 \mathrm{~mm} \mathrm{Mg}^{2+}$. All drugs in these histograms were applied at a concentration of 10 $\mu \mathrm{M} . \boldsymbol{A}$, An ANOVA revealed a significant interaction $\left(F_{(5,35)}=3.52 ; p<0.05\right)$ between drug treatment and the threshold current required to induce an impulse from the $S$ cell, according to the methods described in Figure $5 \mathrm{~A}$. Note in particular that a post hoc analysis using the LSD test confirmed that 5-Me0T caused a significant reduction in current threshold compared with controls $(p<0.05)$ and compared with $5-\mathrm{Me} 0 \mathrm{~T}$ applied simultaneously with pimozide (10 $\mu \mathrm{m} ; p<0.05$ ). There was no significant difference between the 5 -Me0T applied with pimozide and controls ( $p=0.72$ ), and pimozide alone had no effect on current threshold ( $p=0.70)$. $\boldsymbol{B}$, A separate ANOVA showed a significant interaction between drug treatment and the number of impulses elicited from the $S$ cell during a 200 ms current pulse $\left(F_{(5,35)}=4.76 ; p<0.01\right)$, as described by the methods in Figure $5 B$. Post hoc analysis using the LSD test verified that $5-\mathrm{Me} 0 \mathrm{~T}$ caused a significant increase in the number of impulses compared with controls $(p<0.05)$ or 5 -Me0T applied with pimozide $(p<0.001)$. There was no significant difference between 5 -MeOT applied with pimozide and controls ( $p=0.33$ ) or pimozide alone and controls ( $p=$ 0.90 ). The effect of 5 -HT was significantly different from the effect of 5 -HT plus pimozide, with respect to both current threshold and number of impulses $(p<0.05)$. The interaction between the change in the current threshold and the change in the number of impulses was examined across drug conditions using the Pearson's product-moment correlation; the correlation was statistically significant $(r=-0.70 ; p<0.001$, Student's $t$ test). Asterisks indicate significance as follows: ${ }^{*} p<0.05 ;{ }^{* *} p<0.001$. Error bars indicate SEM.

(Burrell and Sahley, 2005) suggests that 5-MeOT may be acting by way of a $5-\mathrm{HT}_{7}$-like receptor. Furthermore, whereas no $5-\mathrm{HT}_{4} \mathrm{R}$ or $5-\mathrm{HT}_{6} \mathrm{R}$ cDNAs have been cloned from any invertebrate to date, $5-\mathrm{HT}_{7} \mathrm{R}$-like $\mathrm{cDNAs}$ have been cloned from the mosquito Aedes aegypti (Pietrantonio et al., 2001) and the nematode Caenorhabditis elegans (Hobson et al., 2003). Pimozide $(\leq 10 \mu \mathrm{M})$, a dopamine receptor antagonist with a particularly high affinity for $5-\mathrm{HT}_{7} \mathrm{R}$, was found to antagonize the $5-\mathrm{HT}_{7}$-like receptor cloned from the mosquito (Lee and Pietrantonio, 2003). Thus, the effects on S cell excitability of 5-MeOT and 5-HT, with and without pimozide, were examined. The experiments were conducted in saline containing $18 \mathrm{mM} \mathrm{Mg}^{2+}$ to prevent any indirect, synaptic effects of the drugs acting on other cells that might synapse on the $\mathrm{S}$ cell. The drugs used, at $10 \mu \mathrm{M}$ each were as follows: 5-HT alone, 5-MeOT alone, pimozide alone, 5-HT with pimozide, 5-MeOT with pimozide, and control (no drugs).

The results of these experiments are summarized in a histogram in Figure 6. An ANOVA revealed the interactions between drug treatment and threshold current $\left(F_{(5,35)}=3.52 ; p<0.05\right)$, and drug treatment and number of impulses $\left(F_{(5,35)}=4.76 ; p<\right.$ $0.01)$, to be statistically significant. The interactions between drug treatment and membrane potential $(p=0.18)$, and drug treatment and input resistance ( $p=0.61$ ), were not significant. Post hoc analysis using the least significant differences (LSD) test was used to compare specific treatment groups with respect to threshold and number of impulses. 5-MeOT caused a significant reduction in current threshold compared with controls $(p<0.05)$ or to 5-MeOT applied with pimozide $(p<0.05)$. When applied simultaneously with pimozide, $5-\mathrm{MeOT}$ did not reduce current threshold compared with controls $(p=0.72)$. Similarly, 5 -MeOT caused a significant increase in the number of impulses compared with controls $(p<0.05)$ or when compared with 5 -MeOT applied simultaneously with pimozide $(p<0.001)$, but when applied simultaneously with pimozide, 5-MeOT did not cause an increase in impulses relative to control ( $p=0.33)$. 5-HT 
appeared to have less potent effects on excitability than equimolar 5-MeOT. Whereas 5-HT was not significantly different from $5-\mathrm{MeOT}$ with respect to decreasing threshold current $(p=0.25)$ or increasing the number of impulses $(p=0.16)$, relative to controls, 5-HT did not cause a significant decrease in threshold current $(p=0.32)$ or number of impulses $(p=0.20)$. The $\mathrm{S}$ cell appears to have a low-affinity 5-HTR that enhances $S$ cell excitability at higher 5-HT concentrations (i.e., the 5- $\mathrm{HT}_{7}$-like receptor) and a high-affinity 5-HTR that decreases S cell excitability at lower 5-HT concentrations (Burrell et al., 2001). It may be that 5 -HT has a less potent effect on the $S$ cell because it activates both receptors, whereas 5-MeOT is selective for the 5- $\mathrm{HT}_{7}$-like receptor. 5-HT did differ significantly from 5-HT applied simultaneously with pimozide, with respect to both threshold $(p<0.05)$ and number of impulses $(p<0.05)$. Pimozide was not different from control as regards either threshold $(p=0.70)$ or number of impulses $(p=0.90)$. A Pearson product-moment correlation analysis, together with a two-sided Student's $t$ test, found a statistically significant inverse relationship between the change in current threshold and the change in the number of impulses across all drug conditions $(r=-0.70 ; p<0.001)$. These results suggest that the effect of 5-HT on $S$ cell excitability is mediated by a $5-\mathrm{HT}_{7}$-like receptor.

To further characterize the pharmacological properties of the 5-HTR responsible for regulating S cell excitability, a highly selective $5-\mathrm{HT}_{7} \mathrm{R}$ antagonist, SB-269970 (5 $\left.\mu \mathrm{M}\right)$, was used. Because experiments described above established that 5-MeOT affects $\mathrm{S}$ cell excitability directly, experiments with SB-269970 were conducted in physiological saline (containing no $\mathrm{MgCl}_{2}$ and $1.8 \mathrm{mM}$ $\mathrm{CaCl}_{2}$ ). Furthermore, because Burrell and Sahley (2005) demonstrated that methysergide blocks the ability of $10 \mu \mathrm{M} 5-\mathrm{HT}$ to enhance the excitability of the $S$ cell, the ability of $100 \mu \mathrm{M}$ methysergide to block the effects of $10 \mu \mathrm{M} 5-\mathrm{MeOT}$ on $\mathrm{S}$ cell excitability was also examined. In saline, $10 \mu \mathrm{M} 5-\mathrm{MeOT}$ decreased the current threshold for $S$ cell impulses by $0.92 \pm 0.03 \mathrm{nA}(n=5)$. In combination with $5 \mu \mathrm{M}$ SB-269970, $10 \mu \mathrm{M}$ 5-MeOT reduced the current threshold by only $0.04 \pm 0.05 \mathrm{nA}(n=7)$. Similarly, 10 $\mu \mathrm{M} 5-\mathrm{MeOT}$ did not significantly reduce current threshold when applied in combination with $100 \mu \mathrm{M}$ methysergide $(0.13 \pm 0.16$ $\mathrm{nA} ; n=5)$. An ANOVA revealed a significant interaction between drug treatments $\left(F_{(2,14)}=38.02 ; p<0.001\right)$. Post hoc analysis using the LSD test verified that the effect of 5-MeOT alone was significantly different from 5-MeOT with SB-266970 $(p<$ 0.001 ) or methysergide $(p<0.001)$, but there was no difference between the two antagonist treatments $(p=0.18)$.

Pimozide, like other neuroleptics in the structural class of diphenylbutylpiperidines, reportedly binds to and possibly blocks certain potassium and calcium ion channels, including G-protein-gated inwardly rectifying and delayed-rectifier potassium channels, and L-type and T-type calcium channels (King et al., 1989; Kobayashi et al., 2000; Santi et al., 2002; Zhang et al., 2003). However, in the present experiments, pimozide appears instead to have impaired the enhancement of S cell excitability through actions on a 5-HT receptor, because pimozide by itself did not affect $S$ cell excitability. Moreover, pimozide mimicked the effects of SB-269970, an aryl sulfonamide, which has no reported effects on ion channels. Also, no changes in action potentials were observed, consistent with a lack of effects on delayedrectifier potassium channels. All of our experiments involving pimozide were conducted in saline containing a 10-fold excess of magnesium to calcium ions, so effects of changes in calciumdependent membrane properties would have been diminished.

Of course, the effect of bath applied 5-HT may differ from the

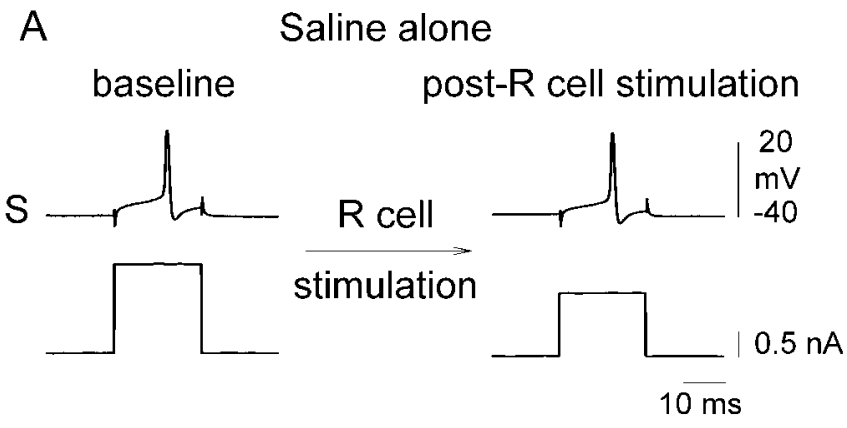

B $\quad 10 \mu \mathrm{M}$ pimozide

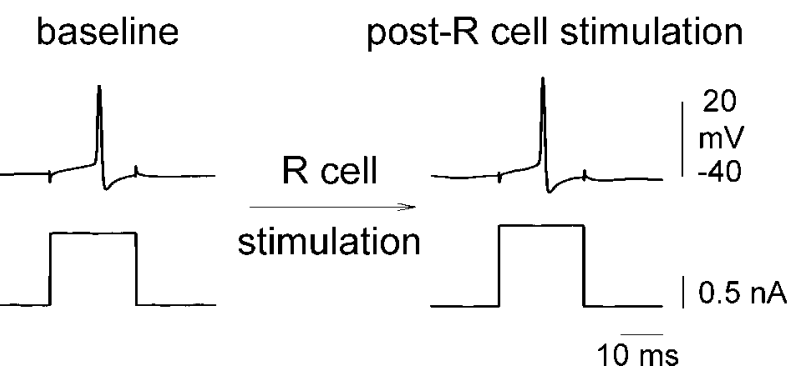

Figure 7. Pimozide blocked the effects of R-cell stimulation on the excitability of the $S$ cell in physiological saline (containing $0 \mathrm{~mm} \mathrm{Mg}^{2+}$ and $1.8 \mathrm{~mm} \mathrm{Ca}^{2+}$ ). $A$, Current threshold required to elicit an action potential from the $S$ cell was measured before and immediately after stimulation of the $R$ cell for $10 \mathrm{~s}$ at $4 \mathrm{~Hz}$. R-cell stimulation caused a mean reduction of $0.33 \pm 0.18 \mathrm{nA}$ in threshold current $(n=5)$. $\boldsymbol{B}$, When ganglia were bathed in saline containing pimozide (10 $\mu \mathrm{m})$, R-cell stimulation caused no significant reduction in threshold current required to produce an action potential $(0.06 \pm 0.05 \mathrm{nA} ; n=6)$. An ANOVA revealed that there was a significant effect of pimozide on changes in excitability after R-cell stimulation $\left(F_{(1,9)}=18.20 ; p<0.01\right)$.

effects of 5-HT released endogenously within the nervous system. Thus, the ability of pimozide to block the increase in excitability of the $\mathrm{S}$ cell observed after $\mathrm{R}$ stimulation was also examined. Following the methods of Burrell et al. (2001), the excitability of the $S$ cell was measured before and immediately after intracellular stimulation of the R cell $(10 \mathrm{~s}, 4 \mathrm{~Hz})$. There was no wash and no delay between R-cell stimulation and the final excitability measurement. Although intracellular stimulation of the $\mathrm{R}$ cell reduced the threshold current required to evoke an $\mathrm{S}$ cell impulse by $0.33 \pm 0.18 \mathrm{nA}(n=5)$ in physiological saline (Fig. $7 A)$, R-cell stimulation did not significantly reduce the threshold current of $S$ cells first exposed to $10 \mu \mathrm{M}$ pimozide for $4 \mathrm{~min}$ (Fig. $7 B)(0.06 \pm$ $0.05 \mathrm{nA} ; n=6)$. An ANOVA confirmed that this effect was statistically significant $\left(F_{(1,9)}=18.20 ; p<0.01\right)$. The input resistance of the $S$ cell increased slightly after R-cell stimulation, both with pimozide $(1.7 \pm 1.1 \mathrm{M} \Omega)$ and without it $(1.7 \pm 0.7 \mathrm{M} \Omega)$, but the effect of pimozide on input resistance was not significant $\left(F_{(5,5)}=2.64 ; p=0.16\right)$. The increase in input resistance may reflect an increase in the quality of impalement over time. Similarly, there was little change in the membrane potential of the $S$ cell after R-cell stimulation, whether pimozide was present (change of $-0.2 \pm 1.1 \mathrm{mV}$ ) or absent (change of $0 \pm 0.7 \mathrm{mV}$ ) from the saline $\left(F_{(6,4)}=0.70 ; p=0.67\right)$.

The change in the number of impulses after R-cell stimulation in saline without pimozide was small (an increase of $1.12 \pm 0.13$ impulses after R-cell stimulation) and not significant. Therefore, it is not surprising that the effect of pimozide on the increase in impulse number after R-cell stimulation was not significant $\left(F_{(1,9)}=1.22 ; p=0.30\right)$. 


\section{Discussion}

Serotonin, sensitization, and positive feedback on the $S$ cell

The results indicate that the excitability of the $S$ cell is regulated by positive feedback. Activity in the $\mathrm{S}$ cell excites the $\mathrm{R}$ cell through the coupling interneurons, thereby increasing the secretion of $5-\mathrm{HT}$ in the ganglion. The 5-HT activates a $5-\mathrm{HT}_{7}$-like receptor on the $S$ cell, causing an increase in cAMP (Burrell and Sahley, 2005). The mechanisms by which 5-HT enhances the excitability of the $S$ cell are unknown (Burrell et al., 2001). The persistence of the 5-HT-mediated changes in excitability in 18 $\mathrm{mM} \mathrm{Mg}{ }^{2+}$ saline is consistent with a mechanism, or set of mechanisms, that are independent of calcium. Although many calcium-dependent processes, such as neurotransmitter release, are blocked by elevated extracellular magnesium ions (Katz, 1962), other processes may not be. For example, trains of impulses in leech sensory neurons induce a long-lasting decrease in input resistance, because of the activation of a calciumdependent potassium current, even in saline containing $20 \mathrm{~mm}$ $\mathrm{Mg}^{2+}$ (Jansen and Nicholls, 1973). Thus, calcium-dependent processes cannot be ruled out as contributing to the enhanced excitability. Regardless of the mechanisms underlying it, the increase in excitability as a result of R-cell activity presumably results in more $S$ cell impulses in response to sensory stimulation, as has been shown for 5-HT (Burrell et al., 2002), thereby promoting greater excitation of motor neurons leading to more pronounced shortening contractions. Although the number of impulses initiated in any single $S$ cell might not increase in response to a given stimulus, because the number of impulses generated by the chain is the sum of the initiations in several ganglia, the overall firing rate will increase if excitability is increased in multiple $S$ cells (Baccus et al., 2001). Even with a sensory stimulus focused in one segment, sensory neurons together will excite $S$ cells in up to four additional segments. Thus, this feedback loop may be important for the full expression of sensitization of reflexive shortening in the leech.

Serotonin-mediated changes in the excitability of the $\mathrm{S}$ cell may also play a role in associative learning in the leech. The shortening reflex can be modified by associative learning (Sahley et al., 1994), and Hebbian-type changes in strength [e.g., longterm potentiation (LTP) and long-term depression] have been demonstrated at synapses between sensory neurons and the $S$ cell (Burrell and Sahley, 2004). Regulation of intrinsic excitability corresponds to a global "gain control" that determines the sensitivity of computer-modeled neurons to Hebbian-type changes in the strength of individual synapses (Siegel et al., 1994). Such a mechanism also evidently operates in the mammalian hippocampus, in which LTP has been well studied between the Schaffer collateral/commissural fibers and CA1 pyramidal cells (Kelso et al., 1986). As in the S cell, the excitability of these pyramidal cells appears to be regulated by activation of the $5-\mathrm{HT}_{7}$ receptor $(\mathrm{Co}-$ lino and Halliwell, 1987; Tokarski et al., 2003).

\section{The coupling interneurons as intermediaries}

Although we cannot rule out the presence of a relatively weak monosynaptic glutamatergic connection from the $\mathrm{S}$ cell onto the $\mathrm{R}$ cell, the bulk of the glutamatergic signaling appears to be via the coupling interneurons. Electron microscopy has shown that the coupling interneurons make and receive chemical synapses (Muller and Scott, 1981). No synaptic target of the coupling interneurons, however, has been found until now. The functional significance of interposing the coupling interneurons between the touch-sensory neurons, the $\mathrm{S}$ cells, and the $\mathrm{R}$ cells is not yet clear, but they might help to isolate the $S$ cell itself from imped- ance changes and reduce the load on the axial current of the axon Specifically, the coupling interneurons may distance the $S$ cells from impedance changes associated with synaptic potentials, similar to the way the electrotonic distance of a dendrite can insulate the soma from impedance change associated with a distally generated EPSP (Rall et al., 1967). Such impedance changes, were they to occur in the $S$ cell, could increase the risk of action potential propagation failure. Thus, the coupling interneurons may integrate inputs to the S-cell network and provide local control on individual synaptic outputs. But equally as important for the $S$ cell, which rapidly conveys impulses through the ganglion and along the nerve cord, the coupling interneurons enable the $\mathrm{S}$ cell to have more widespread synaptic output across the ganglion with minimal loss of current for its rapidly conducting impulse: the fastest in the animal.

\section{Feedback mechanisms and learning}

Just as negative feedback occurs widely in biological systems to confer stability, positive feedback is also of fundamental importance, particularly for operation of the nervous system. Not only are such basic elements as action potentials generated by positive feedback, but it is increasingly recognized that mechanisms thought to underlie learning and formation of memories operate by positive feedback (Lisman, 1999; Lisman and Fallon, 1999; Lisman et al., 2002; Routtenberg and Rekart, 2005). For the S cell, which is involved in simple learning, positive feedback is at the level of a small cellular network, rather than the synapse itself. Because the gain of the positive feedback is limited, the network can return to its original state sometime after sensory input has ended, depending on the duration of the effects of $5 \mathrm{HT}$, which have been shown in previous reports to last several tens of minutes (Burrell et al., 2001, 2002). In this way, positive feedback confers both stability and an additional route for sensory input.

\section{References}

Aizenman CD, Linden DJ (2000) Rapid, synaptically driven increases in the intrinsic excitability of cerebellar deep nuclear neurons. Nat Neurosci 3:109-111.

Baccus SA, Burrell BD, Sahley CL, Muller KJ (2000) Action potential reflection and failure at axon branch points cause stepwise changes in EPSPs in an interneuron essential for learning. J Neurophysiol 83:1693-1700.

Baccus SA, Sahley CL, Muller KJ (2001) Multiple sites of action potential initiation increase neuronal firing rate. J Neurophysiol 86:1226-1236.

Burrell BD, Sahley CL (2004) Multiple forms of long-term potentiation and long-term depression converge on a single interneuron in the leech CNS. J Neurosci 24:4011-4019.

Burrell BD, Sahley CL (2005) Serotonin mediates learning-induced potentiation of excitability. J Neurophysiol 94:4002-4010.

Burrell BD, Sahley CL, Muller KJ (2001) Non-associative learning and serotonin induce similar bi-directional changes in excitability of a neuron critical for learning in the medicinal leech. J Neurosci 21:1401-1412.

Burrell BD, Sahley CL, Muller KJ (2002) Differential effects of serotonin enhance activity of an electrically coupled neural network. J Neurophysiol 87:2889-2895.

Burrell BD, Sahley CL, Muller KJ (2003) Progressive recovery of learning during regeneration of a single synapse in the medicinal leech. J Comp Neurol 457:67-74.

Colino A, Halliwell JV (1987) Differential modulation of three separate K-conductances in hippocampal CA1 neurons by serotonin. Nature 328:73-77.

Desai NS, Rutherford LC, Turrigiano GG (1999) Plasticity in the intrinsic excitability of cortical pyramidal neurons. Nat Neurosci 2:515-520.

Duan Y, Panoff J, Burrell BD, Sahley CL, Muller KJ (2005) Repair and regeneration of functional synaptic connections: cellular and molecular interactions in the leech. Cell Mol Neurobiol 25:441-450.

Frankenhaeuser B, Hodgkin AL (1957) The action of calcium on the electrical properties of squid axons. J Physiol (Lond) 137:218-244. 
Gu X, Macagno ER, Muller KJ (1989) Laser microbeam axotomy and conduction block show that electrical transmission at a central synapse is distributed at multiple contacts. J Neurobiol 20:422-434.

Gu X, Muller KJ, Young SR (1991) Synaptic integration at a sensory-motor reflex in the leech. J Physiol (Lond) 441:733-754.

Hobson RJ, Geng J, Gray AD, Komuniecki RW (2003) SER-7b, a constitutively active G $\alpha$ s coupled 5-HT7-like receptor expressed in the Caenorhabditis elegans M4 pharyngeal motor neuron. J Neurochem 87:22-29.

Jansen JK, Nicholls JG (1973) Conductance changes, an electrogenic pump and the hyperpolarization of leech neurones following impulses. J Physiol (Lond) 229:635-655.

Katz B (1962) The transmission of impulses from nerve to muscle, and the subcellular unit of synaptic action. Proc R Soc Lond B Biol Sci 155:455-477.

Kelso SR, Ganong AH, Brown TH (1986) Hebbian synapses in hippocampus. Proc Natl Acad Sci USA 83:5326-5330.

King VF, Garcia ML, Shevell JL, Slaughter RS, Kaczorowski GJ (1989) Substituted diphenylbutylpiperidines bind to a unique high affinity site on the L-type calcium channel. Evidence for a fourth site in the cardiac calcium entry blocker receptor complex. J Biol Chem 264:5633-5641.

Kobayashi T, Ikeda K, Kumanishi T (2000) Inhibition by various antipsychotic drugs of the G-protein-activated inwardly rectifying $\mathrm{K}^{+}$(GIRK) channels expressed in Xenopus oocytes. Br J Pharmacol 129:1716-1722.

Kuffler SW, Potter DD (1964) Glia in the leech central nervous system: physiological properties and neuron-glia relationship. J Neurophysiol 27:290-320.

Lee DW, Pietrantonio PV (2003) In vitro expression and pharmacology of the 5-HT7-like receptor present in the mosquito Aedes aegypti tracheolar cells and hindgut-associated nerves. Insect Mol Biol 12:561-569.

Lent CM, Zundel D, Freedman E, Groome JR (1991) Serotonin in the leech central nervous system: Anatomical correlates and behavioral effects. J Comp Physiol A Neuroethol Sens Neural Behav Physiol 168:191-200.

Lisman J, Schulman H, Cline H (2002) The molecular basis of CaMKII function in synaptic and behavioral memory. Nat Rev Neurosci 3:175-190.

Lisman JE (1999) Relating hippocampal circuitry to function: recall of memory sequences by reciprocal dentate-CA3 interactions. Neuron 22:233-242.

Lisman JE, Fallon JR (1999) What maintains memories? Science 283:339-340.

Liu Y, Nicholls J (1989) Steps in the development of chemical and electrical synapses by pairs of identified leech neurons in culture. Proc R Soc Lond B Biol Sci 236:253-268.

Macagno ER, Muller KJ, Pitman RM (1987) Conduction block silences parts of a chemical synapse in the leech central nervous system. J Physiol (Lond) 387:649-664.

Marinesco S, Carew TJ (2002) Serotonin release evoked by tail nerve stimulation in the CNS of Aplysia: characterization and relationship to heterosynaptic plasticity. J Neurosci 22:2299-2312.

Modney BK, Sahley CL, Muller KJ (1997) Regeneration of a central synapse restores non-associative learning. J Neurosci 17:6478-6482.
Muller KJ, Scott SA (1981) Transmission at a "direct" electrical connexion mediated by an interneurone in the leech. J Physiol (Lond) 311:565-583.

Nicholls JG, Purves D (1970) Monosynaptic chemical and electrical connexions between sensory and motor cells in the central nervous system of the leech. J Physiol (Lond) 209:647-667.

O’Gara BA, Illuzzi FA, Chung M, Portnoy AD, Fraga K, Frieman VB (1999) Serotonin induces four pharmacologically separable contractile responses in the pharynx of the leech Hirudo medicinalis. Gen Pharmacol 32:669-681.

Pietrantonio PV, Jagge C, McDowell C (2001) Cloning and expression analysis of a 5HT7-like serotonin receptor cDNA from mosquito Aedes aegypti female excretory and respiratory systems. Insect Mol Biol 10:357-369.

Rall W, Burke RE, Smith TG, Nelson PG, Frank K (1967) Dendritic location of synapses and possible mechanisms for the monosynaptic EPSP in motoneurons. J Neurophysiol 30:1169-1193.

Raymond JR, Mukhin YV, Gelasco A, Turner J, Collinsworth G, Gettys TW, Grewal JS, Garnovskaya MN (2001) Multiplicity of mechanisms of serotonin receptor signal transduction. Pharmacol Ther 92:179-212.

Routtenberg A, Rekart JL (2005) Post-translational protein modification as the substrate for long-lasting memory. Trends Neurosci 28:12-19.

Sahley CL, Modney BK, Boulis NM, Muller KJ (1994) The S cell: an interneuron essential for sensitization and full dishabituation of leech shortening. J Neurosci 14:6715-6721.

Santi CM, Cayabyab FS, Sutton KG, McRory JE, Mezeyova J, Hamming KS, Parker D, Stea A, Snutch TP (2002) Differential inhibition of T-type calcium channels by neuroleptics. J Neurosci 22:396-403.

Shaw BK, Kristan Jr WB (1995) The whole-body shortening reflex of the medicinal leech: motor pattern, sensory basis, and interneuronal pathways. J Comp Physiol A Neuroethol Sens Neural Behav Physiol 177:667-681.

Siegel M, Marder E, Abbott LF (1994) Activity-dependent current distributions in model neurons. Proc Natl Acad Sci USA 91:11308-11312.

Tokarski K, Zahorodna A, Bobula B, Hess G (2003) 5-HT7 receptors increase the excitability of rat hippocampal CA1 pyramidal neurons. Brain Res 993:230-234.

Trueta C, Mendez B, De Miguel FF (2003) Somatic exocytosis of serotonin mediated by L-type calcium channels in cultured leech neurones. J Physiol (Lond) 547:405-416.

Trueta C, Sanchez-Armass S, Morales MA, De Miguel FF (2004) Calciuminduced calcium release contributes to somatic secretion of serotonin in leech Retzius neurons. J Neurobiol 61:309-316.

Weeks JC (1981) Neuronal basis of leech swimming: separation of swim initiation, pattern generation, and intersegmental coordination by selective lesions. J Neurophysiol 45:698-723.

Wessel R, Kristan Jr WB, Kleinfeld D (1999) Supralinear summation of synaptic inputs by an invertebrate neuron: dendritic gain is mediated by an “inward rectifier" $\mathrm{K}^{+}$current. J Neurosci 19:5875-5888.

Zhang ZH, Lee YT, Rhodes K, Wang K, Argentieri TM, Wang Q (2003) Inhibitory effects of pimozide on cloned and native voltage-gated potassium channels. Mol Brain Res 115:29-38. 